\title{
Provincial health accounts in Kerman, Iran: an evidence of a "mixed" healthcare financing system
}

\author{
Mohammad Hossein Mehrolhassani ${ }^{1}$, Mohammad Jafari ${ }^{2}$, Javad Zeinali ${ }^{3}$, Mina Ansari ${ }^{4, \star}$
}

\begin{abstract}
Background: Provincial Health Accounts (PHA) as a subset of National Health Accounts (NHA) present financial information for health sectors. It leads to a logical decision making for policy-makers in order to achieve health system goals, especially Fair Financial Contribution (FFC). This study aimed to examine Health Accounts in Kerman Province. Methods: The present analytical study was carried out retrospectively between 2008 and 2011. The research population consisted of urban and rural households as well as providers and financial agents in health sectors of Kerman Province. The purposeful sampling included 16 provincial organizations. To complete data, the report on Kerman household expenditure was taken as a data source from the Governor-General's office. In order to classify the data, the International Classification for Health Accounts (ICHA) method was used, in which data set was adjusted for the province.

Results: During the study, the governmental and non-governmental fund shares of the health sector in Kerman were $27.22 \%$ and $72.78 \%$ respectively. The main portion of financial sources (59.41) was related to private household funds, of which the Out-of-Pocket (OOP) payment mounted to $92.35 \%$. Overall, $54.86 \%$ of all financial sources were covered by OOP. The greatest portion of expenditure of Total Healthcare Expenditures (THEs) (65.19\%) was related to curative services.

Conclusion: The major portion of healthcare expenditures was related to the OOP payment which is compatible with the national average rate in Iran. However, health expenditure per capita, was two and a half times higher than the national average. By emphasizing on Social Determinant of Health (SDH) approach in the Iranian health system, the portion of OOP payment and curative expenditure are expected to be controlled in the medium term. It is suggested that PHA should be examined annually in a more comprehensive manner to monitor initiatives and reforms in healthcare sector.

Keywords: Provincial Health Accounts (PHA), Kerman Province, Out-of-Pocket (OOP) Payment, Health Expenditure Per Capita

Copyright: (C) 2014 by Kerman University of Medical Sciences

Citation: Mehrolhassani MH, Jafari M, Zeinali J, Ansari M. Provincial health accounts in Kerman, Iran: an evidence of a "mixed" healthcare financing system. Int J Health Policy Manag 2014; 2: 69-74. doi: 10.15171/ijhpm.2014.17
\end{abstract}

Article History:

Received: 5 November 2013 Accepted: 15 February 2014 ePublished: 23 February 2014

*Correspondence to:

Mina Ansari

Email: m.ansari@kmu.ac.ir

\section{Introduction}

Financing is one of the main four functions in health system which can realize equitable accessibility, improved quality and efficiency in healthcare services (1). Moreover, the increasing burden of diseases particularly non-communicable ones has led to poor health and a sharp rise in financial pressures in developing countries (2). Moreover, these financial pressures can lead to high Out-of-Pocket (OOP) payment which can also make potential risk to catastrophic costs ${ }^{1}$ for households particularly poor people. Therefore, many low-and middleincome countries such as those in the Middle East and North Africa (MENA), are struggling to reform their health systems through equity improvement, cost containment, and financial sustainability of their healthcare services (4). In this process, policy-makers would need certain tools for wise management of their resources in health sectors $(2,5)$. Practical tools for policy-makers can transplant the complex interactions of these reforms and those in the resource allocation processes (6). National Health Accounts (NHA) is one of the accepted financing tools at the international level which is necessary

1. Catastrophic expenditure is defined as OOP health payment exceeding $40 \%$ of a household's non-subsistence spending. Impoverishment measures the percentage of households pushed below the poverty line due to OOP (3) for the health system stewardship (7-9). This tool is designed systematically, comprehensively, and compatibly (10) with the consistent monitoring of resource flows (11) and health funds in the health system of a country in order to follow up, gather, measure, and estimate financial flows of the health system (9, 11,12). This flow represents the financial sources, financial agents (11), preventive and curative service providers (9), and health system functions for stakeholders and decision-makers (11) during a certain period of time (13). According to Berman (14), NHA responds to the recognition of the drawbacks for optimum management, mobilization and allocation of health sector resources, and also source origins and usages (14). Therefore, the purpose of designing NHA is to create a special tool (8) and framework (15) to obtain information about the process of health policy: designing and implementing policy, policy dialogue, healthcare interventions, monitoring and evaluating (16) as well as measuring resources and their flows systematically (12).

NHA serves to answer the following main questions put forward by policy-makers:

1. How are resources mobilized and managed for the health system? 
2. Who pays and how much is paid for healthcare?

3. Who provides goods and services, and what resources do they use?

4. How are healthcare funds distributed across the different services, interventions, and activities that the health system produces?

5. Who benefits from healthcare expenditure? (16-18)

The necessary framework for NHA or the regional and Provincial Health Accounts (PHA) includes a matrix of operational categories which classifies and defines sources of health funds and services purchased with them. These accounts gather a picture of National Health Economics (NHE) in one place, accordance with the national income (19). The related information is collected in nine tables, four of which would be used in order to produce all NHA reports. These tables show four types or dimensions of healthcare actors. These dimensions which include financial sources, financial agents, providers and functions will be seen frequently in estimations (20).

The NHA topic is a considerable issue in the field of health system financing with a record of about 50 years. Since 1964, the US Department of Health and Human Services has published an annual series of statistics presenting total national health expenditures (19). Since 1997, six regional national health account networks have been established primarily aiming at the execution of NHA in member countries (21). In this regard, the following experiences of member countries could represent the importance of this issue:

Since "province" is a unit of political and administrative divisions in Iran, PHA are the same as national regional accounts which illustrate the situation of economical and financial health sectors at provincial level and prepare reliable and compatible statistics for policy making at this level (22). Eventually, PHA studies can provide useful information and a clear image as evidence for policy-makers to make effective decisions on the health system functions (stewardship, resource generation, financing, and service provision) particularly at local level. Therefore, we aimed to study the PHA in Kerman Province of Iran.

\section{Kerman Province}

Kerman, being one of 31 provinces, is located in southeastern Iran. It is the second largest province which embraces more than $11 \%$ of the area of Iran. In 2011, the population of the province was 2,938,988 (1482339 male, 1456649 female) in 786,400 households, with 1684982 (57.33\%) living in urban areas, $1242344(42.27 \%)$ in the rural vicinities and $6082(0.20 \%)$ being non-residents.

Based on Iran's health system, there are many actors as providers and purchasers in the public and private sectors and there are pluralistic health insurance organizations which play a role in providing and financing healthcare. Iran's health system is primarily dominated by the government's role. The structure of the health system of Iran has three macro (national), meso (provincial or regional) and micro (local or district) levels. It is mentioned that Medical Science Universities are main public organizations in provinces (meso level). It should also be noted that, in Iranian health sector, educational system is integrated with health service systems (22).

\section{Methods}

The present analytical study was carried out retrospectively from 2008 to 2011 . The research population consisted of 16 domestic organizations, institutions, firms and corporations including the Governor-General's office, provincial Medical Universities (Kerman, Jiroft, and Rafsanjan), Armed Forces Medical Services Organization, Imam Khomeini Charity Committee, Foundation of Martyrs and Veterans Affair, Medical Services Insurance Organization (MSIO), Social Security Organization (SSO), Coal Miner Insurance Company, Copper Miners Insurance Company, private supplementary insurance companies, non-profit institutions which serve households, banks, other supplementary insurance companies and other public organizations.

Identifying health financial agents was the first step in conducting the study (after consultation with team members) by using Financial Agents Identification Questionnaire and NHA tables. Then, the relevant health expenditure information was gathered from the identified domestic organizations, institutions, firms and corporations in the above-mentioned period. Moreover, the information regarding Kerman province households' expenditure was obtained from the reports of household expenditure calculation which was prepared at Statistics and Information Office of Kerman Governor-General. This information was prepared from samples shown in Table 1. Ultimately, the gathered data was used to complete the main project tables which were taken from NHA tables. In order to prepare these tables, NHA guide was applied. This guideline uses The International Classification for Health Accounts (ICHA) in order to introduce financial sources, financial agents, providers, and functions which authorize countries to enter new levels $(1,2$, or 3$)$ in accordance with their own situations. In order to localize these tables so as to be used at provincial levels, tables related to functions, healthcare providers, and financial sources were kept at three levels, while the financial agent tables were promoted to 5 levels. Definitive data was available to researchers from all financial agents except for Foundation of Martyrs and Veterans Affair (for unavailability of financial data) which compelled researchers to estimate its data.

Table 1. Sample numbers of household expenditure report

\begin{tabular}{lcccc}
\hline \multirow{2}{*}{ Year } & \multicolumn{2}{c}{ Population numbers } & \multicolumn{2}{c}{ Sample numbers } \\
\cline { 2 - 5 } & urban & rural & urban & rural \\
\hline $2008-9$ & 411259 & 260797 & 574 & 903 \\
$2009-10$ & 423683 & 269256 & 525 & 782 \\
$2010-1$ & 436109 & 278236 & 700 & 820 \\
\hline
\end{tabular}

Note: Household expenditure report was prepared at Statistics and Information Office of Kerman Governor-General. Available from http://amar.kr.ir/ 
The main limitation of this study was the lack of reliable data on the health providers (e.g. hospitals); thus, it was not possible to analyze the provider and function sheets.

\section{Results}

According to Table 2, General Health Expenditure (GHE) had an increasing trend in Kerman province during 2008-11. The share of Total Health Expenditure (THE) and Total Current Health Expenditure (TCHE) as a percentage of GHE declined in 2009-10, but increased again in 2010-1.

Authors found that total financial circulation in health sector from 2008 to 2011 amounted to 5,632-6,509 and 8,087 billion Rials I.R.I, respectively. In 2008-9 (considering a population of 2,722,291), GHE per capita and THE per capita were 2,068,914 and 1,847,159 Rials, respectively. In 2009-10 (considering a population of 2,759,901), GHE per capita and THE per capita were 2,358,680 and 1,692,490 Rials, respectively. In 2010-1 (considering a population of 2,947,346), GHE per capita and THE per capita were $2,744,058$ and 2,406,840 Rials, respectively.

Table 3 shows that during the study period, the nongovernmental sector acquired a greater portion of health expenditure than that of the governmental sector (by the average of $72.78 \%$ ).

As shown in Figure 1, during study periods, the highest financial burden of health expenditure was experienced by households, the domestic government, and employers at $59.41 \%, 27.22 \%$ and $13.35 \%$, respectively. In the mentioned period, OOP dedicated a share of about $54.86 \%$; the domestic government funds dedicated a share of twofold compared to employer funds; total household funds were twice as much as domestic government funds and five times as much as employer funds.

As shown in Table 4, except the OOP payment (54.86\%), the most share of health financing in Kerman province was dedicated to provincial Medical Universities (average
18.23\%), the MSIO (average 10.14\%) and the SSO (average 9.93\%).

According to Figure 2, curative service expenditure obtained the main portion of THE (65.19\%) during the mentioned period. After that, the most expenditures were as follows: outpatients drug expenditure (8.33\%), medical education and health personnel training expenditure (5.79\%), capital formation expenditures (1.54\%), and finally, Research and Development (R\&D) expenditure (0.04\%).

It can be deduced that the highest and the lowest expenditure amounts belonged to curative services and $R \& D$, respectively.

\section{Discussion}

Being the most important tool (23), PHA helps health sector policy-makers, as its end users (20), analyze health sector, facilitate the understanding of dynamics and financing in health sectors in provincial levels (23), improve the performance of health systems, and make evidence-informed policies and decisions $(13,21)$ more efficient resources $(12)$. This study revealed that the share of THE as a percentage of GDP was $6.92 \%$ for Kerman province, while it was $5.83 \%$ for Iran (24), 5.4\% for low-income countries, and 8.5\% for global reports in 2008 (25). The THE per capita was 183 US dollars for Kerman province in 2011; it was equal to 305 US dollars in 2008 for Iran (24), 32 US dollars for low-income countries, and 854 US dollars for global records (25).

The results also indicated that a high percentage of financial resources of the health sector in Kerman province financed by people; was $54.86 \%$ in the current study. Iranian NHA in 2008 was reported to be about $53.56 \%$ (24). Furthermore, the report of World Bank in 2008 revealed that in global and low-income countries, the OOP was around $19.5 \%$ and $51 \%$, respectively which were less than current study.

General Public Health Expenditure (GPHE) as a percentage of THE is another indicator which was reported $29 \%$ for Iran in 2005 (25); in this study, it was $28 \%$ for Kerman province.

Table 2. The share of THE and TCHE as a percentage of GHE in Kerman Province during 2008-11(Values are in billion Rials, I.R.I)

\begin{tabular}{lccccc}
\hline Year & GHE & THE & The Share of THE from GHE & TCHE & The Share of TCHE from GHE \\
\hline $2008-9$ & 5,632 & 5,028 & 89.28 & 4,948 & 87.85 \\
$2009-10$ & 6,509 & 4,671 & 71.76 & 4,583 & 70.41 \\
$2010-1$ & 8,087 & 7,093 & 87.71 & 7,001 & 86.57 \\
\hline
\end{tabular}

Note: Average Currency Rate, Iran; 2008-11: *1 US dollar 15000 I.R.I Rials, PPP 0.4 US dollar for I.R.I, 1 PPP 600 I.R.I Rials

Table 3. Financial burden of health expenditure in Kerman Province during 2008-11 (Values are in billion Rials, I.R.I)

\begin{tabular}{lcc}
\hline Year & Governmental Sector & Non-Governmental Sector \\
\hline $2008-9$ & 1,402 & 4,229 \\
$2009-10$ & 1,860 & 4,649 \\
$2010-1$ & 2,244 & 5,843 \\
\hline
\end{tabular}

Note: Average Currency Rate, Iran; 2008-11: *1 US dollar 15000 I.R.I Rials, PPP 0.4 US US dollar for I.R.I, 1 PPP 600 I.R.I Rials 


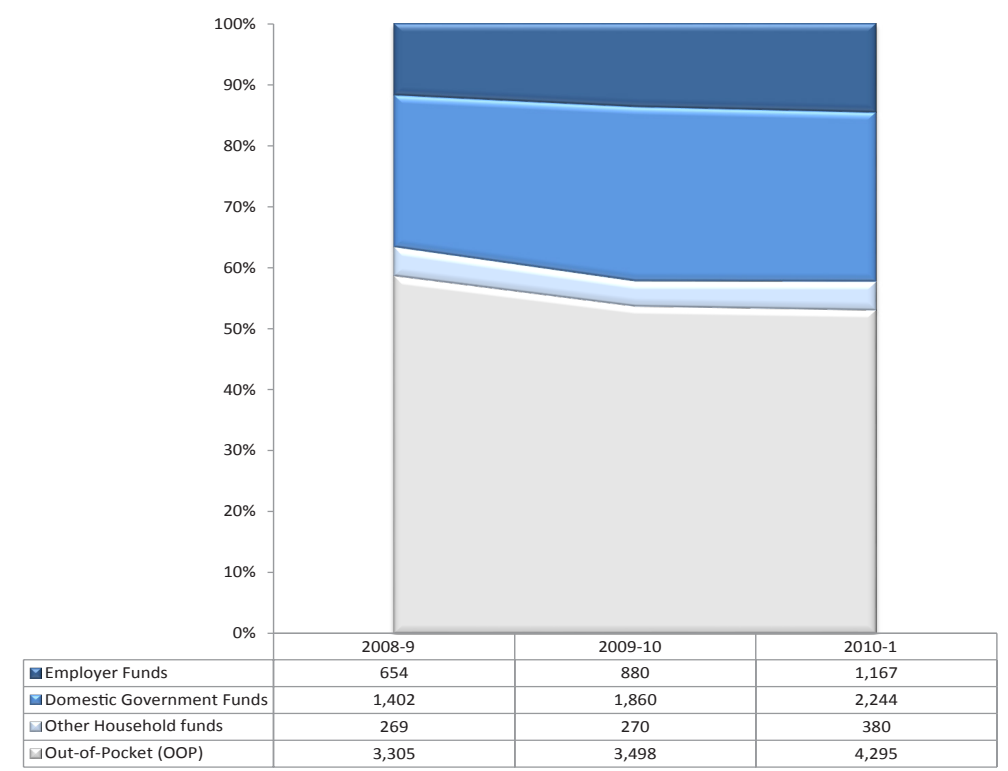

Figure 1. Health Expenditure trend according to financial sources in the Kerman Province during 2008-11

Table 4. Share of health financing in Kerman Province during 2008-11 (Values are in billion Rials, I.R.I)

\begin{tabular}{|c|c|c|c|c|c|c|}
\hline \multirow{2}{*}{ Financial Agents } & \multicolumn{2}{|c|}{ 2008-9 } & \multicolumn{2}{|c|}{ 2009-10 } & \multicolumn{2}{|c|}{ 2010-1 } \\
\hline & Values & $\%$ & Values & $\%$ & Values & $\%$ \\
\hline OOP & 3,305 & $\underline{58.68}$ & 3,498 & $\underline{53.74}$ & 4,295 & $\underline{53.11}$ \\
\hline Provincial Medical Universities & 941 & $\underline{16.72}$ & 1,191 & $\underline{18.30}$ & 1,592 & $\underline{19.6}$ \\
\hline Kerman University of Medical Sciences & 786 & 13.96 & 983 & 15.12 & 1,122 & 13.88 \\
\hline Jiroft University of Medical Sciences & $*$ & $*$ & $*$ & $*$ & 187 & 2.32 \\
\hline Rafsanjan University of Medical Sciences & 155 & 2.76 & 207 & 3.18 & 282 & 3.49 \\
\hline SSO & 517 & $\underline{9.18}$ & 683 & $\underline{10.49}$ & 817 & $\underline{10.11}$ \\
\hline SSO-Direct Care & 182 & 3.24 & 232 & 3.57 & 274 & 3.40 \\
\hline SSO-Indirect Care & 334 & 5.94 & 450 & 6.92 & 542 & 6.71 \\
\hline MSIO & 514 & $\underline{9.13}$ & 692 & 10.64 & 862 & 10.66 \\
\hline Public Insurance Companies & 247 & 4.40 & 322 & 4.96 & 342 & 4.24 \\
\hline Private Supplementary Insurance Companies & 41 & 0.74 & 47 & 0.73 & 83 & 1.03 \\
\hline Other Public Organizations & 40 & 0.72 & 44 & 0.69 & 52 & 0.64 \\
\hline Total & \multicolumn{2}{|c|}{5,632} & \multicolumn{2}{|c|}{6,509} & \multicolumn{2}{|c|}{8,087} \\
\hline
\end{tabular}

*The university was not established

Also, this study showed that curative services included the main share of health sources $(65.19 \%)$ at the provincial level. On the other hand, preventive and public health functions in the provincial level consisted of the least portion of sources. At the national level, curative services had the most portion of THE (57\%) in 2008 (24).

Iranian policy-makers have targeted the goals of the $4^{\text {th }}$ (200711 ) and $5^{\text {th }}$ National Development Program (2011-5) as follow:

- Reducing OOP payment (as a percentage of THE) to $30 \%$

- Decreasing the population faced with catastrophic health expenditures to $1 \%$

- Increasing government contribution to the share of health expenditure as a percentage to $50 \%$ by the end of the program (1).

This study showed that in spite of passed rules during past years, there is a significant gap between the above targets and the current situation yet. In summary, this indicates a system failure to achieve equity in health. Some of these failures might be arisen from payment system for healthcare provider (26), breadth and depth of health insurance schemes (27) referral 


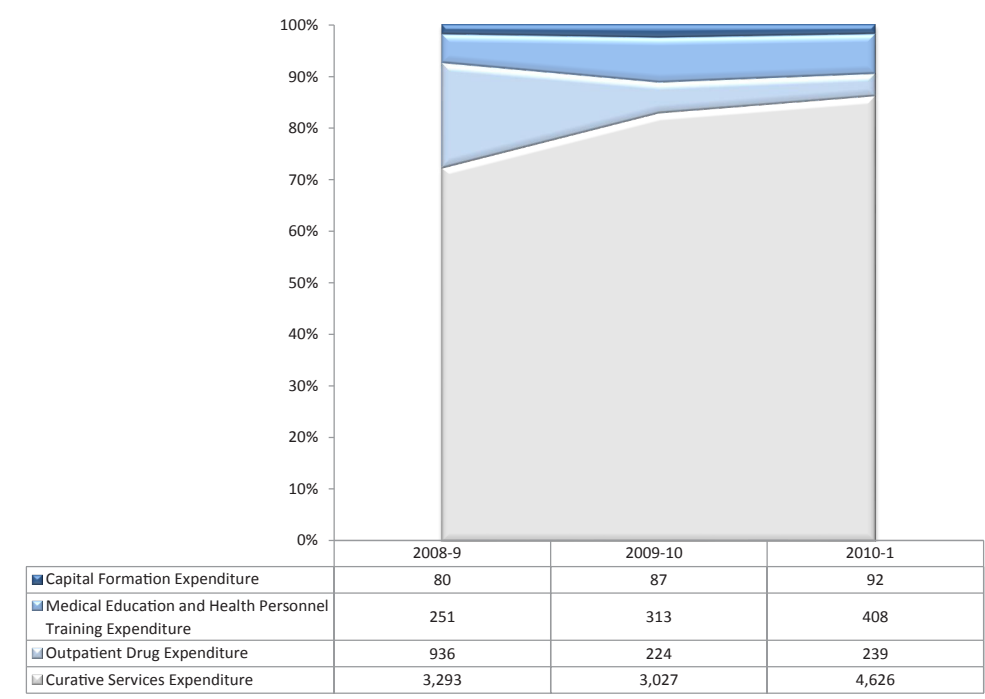

Figure 2. The Kerman Province health expenditure trend according to health functions during 2008-11

system, burden and pattern of diseases in the population (3), government's role in financing and providing services as well as the interaction of the public and unregulated private sectors in service provision (28). This requires further studies to be conducted in other provinces.

\section{Conclusion}

Healthcare financing in Iran is considered as a mixed model in which health resources are mobilized by general revenue of government, social insurances and private sector. As compared with World Bank report, indicators of this study were financially near to low-income countries level.

Low share of government for health financing, high share of OOP payment, and the weak role of insurance in risk polling indicate that there are failures in financing and the objective "equitable participation in financing" has not been met.

To accomplish the equitable accessibility for health services and fair financial protection, PHA and NHA studies can provide evidence for policy-makers particularly developing countries which monitor and evaluate the current situation to apply some appropriate interventions.

\section{Acknowledgements}

Authors would like to thank all their colleagues at Kerman Province governor-general's office, Budget and Performance Monitoring Center of Ministry of Health and Medical Education, Future Studies in Health Research Center of Kerman University of Medical Sciences, and MSIO, for their sincere cooperation.

\section{Ethical issues}

The Ethics Committee of Kerman University of Medical Sciences approved the study (Project No: 91.276).

\section{Competing interests}

The authors declare that they have no competing interests.

\section{Authors' contributions}

MHM initiated the idea. MJ and JZ facilitated the process of data gathering. MA contributed to the literature review, the development of the protocol and managing the data gathering. MHM contributed to study administration, data analysis, interpretation of results and writing the first draft of the manuscript with MA, MJ and JZ. All authors reviewed the final manuscript. MHM and MA are the study guarantors.

\section{Authors' affiliations}

${ }^{1}$ Research Center for Modeling in Health, Institute for Futures Studies in Health, Kerman University of Medical Sciences, Kerman, Iran. ${ }^{2}$ Research Center for Health Services Provision Management, Kerman University of Medical Sciences, General Department of Medical Insurance Services, Kerman, Iran. ${ }^{3}$ Kerman Province Department of General of Medical Insurance, Kerman, Iran. ${ }^{4}$ Research Center for Health Services Management, Institute for Futures Studies in Health, Kerman University of Medical Sciences, Kerman, Iran.

\section{References}

1. Iranian Ministry of Health \& Medical Education (IMHME). Fifth 5-year Development Program of Iran. Tehran: Ministry of Health \& Medical Education; 2009.

2. Glenngård AH, Hjalte F. Use of National Health Accounts: the Case of Uganda. Stockholm: Sida; 2006.

3. Nekoei Moghadam M, Banshi M, Akbari Javar M, Amiresmaili M, Ganjavi S. Iranian household financial protection against catastrophic health care expenditures. Iranian J Publ Health 2012 ; 41: 62-70.

4. De S, Shehata I. Comparative Report of National Health Accounts (NHA): Findings from Eight Countries in the Middle East and North Africa. Bethesda, MD: Partnerships for Health Reform Project, Abt Associates Inc; 2001.

5. Nandakumar AK, Partners for Health Reformplus. Synthesis of findings from NHA studies in twenty-six countries. Maryland: Partners for Health Reformplus, Abt Associates; 2004.

6. Poullier JP, Hernandez P, Kawabata K. National Health Accounts: Concepts, Data Sources and Methodology. Geneva: WHO; 2002.

7. World Health Organization (WHO). Guid to producing regional health accounts within the national health accounts framework. Geneva: WHO; 2008.

8. World Health Organization (WHO). Guide to producing child health subaccounts within the national health accounts framework. Geneva: WHO; 2012.

9. World Health Organization (WHO). Iraq National Health Account 2008. Geneva: WHO; 2011.

10. World Health Organization (WHO). Guid to produceing national health accounts: with special applications for low-income and middle-income countries. Geneva: WHO; 2003.

11. World Health Organization (WHO). Guid To Producing Reproductive Health Subaccounts Within The National Health Accounts Framework. Geneva: World Health Organization; 2009.

12. Izazola-Licea JA, Avila-Figueroa C, Arán D, Piola S, Perdomo R, 
Hernandez P, et al. Country response to HIVIAIDS: national health accounts on HIVIAIDS in Brazil, Guatemala, Honduras, Mexico and Uruguay. AIDS 2002; 16: S66-75.

13. Lie GSS, Ravishankar N, Benezet M, Offosse Mj, Asbu EZ, Lwanga D. Developing a resource tracking system for measuring spending on nutrition in low - and middle - income countries. Geneva: WHo; 2011.

14. Rannan-Eliya RP, Nada KH, Kamal AM, Ali Al. Egypt National Health Accounts 1994-95 [internet]. 1997. Available from: http:// www.healthsystems2020.org/files/1304_file_Sir3.pdf

15. Health Systems 20/20. National Health Accounts and Public Expenditure Reviews: Redundant or Complementary Tools? [internet]. 2009. Available from: http://www.healthsystems2020. org/files/2240_file_NHA_PER_Brief_REV.pdf

16. Partners For Health Reformplus. Understanding National Health Accounts: The Methodology and Implementation Process [internet]. 2003. Available from: http://www.phrplus.org/Pubs/prim1.pdf

17. Soyibo A. National Health Accounts of Nigeria, 1998-2002. Geneva: WHO; 2005.

18. Zere E, Walker O, Kirigia J, Zawaira F, Magombo F, Kataika E. Health financing in Malawi: Evidence from National Health Accounts. BMC Int Health Hum Rights 2010; 10: 27.

19. Lazenby HC, Levit KR, Waldo DR, Adler GS, Letsch SW, Cowan CA. National health accounts: lessons from the U.S. experience. Health Care Financ Rev 1992; 13: 89-103.

20. Patrtners For Health Reformplus. National Health Accounts:
Trainer Manual [internet]. 2004. Available from: http://www. healthsystems 2020.org/files/1781 file Tool002 fin.pdf

21. Glenngard AH, Hjalta F, Hjortsberg C. National Health Accounts: Demand and Use of Health Expenditure Data. Lund: The Swedish Institute for Health Economics; 2007.

22. Khayatzadeh-Mahani A, Fotaki M, Harvey G. Priority setting and implementation in a centralized health system: a case study of Kerman province in Iran. Health Policy Plan 2013; 28: 480-94.

23. Rannan-Eliya RP, Berman PA, Somanathan A. Health Accounting: A Comparison of the System of National Accounts and National Health Accounts Approaches. Maryland: Partnerships for Health Reform; 1997.

24. Statistical Center of Iran. [National Health Accounts: years 20022008]. Tehran: Statistical Center of Iran; 2011.

25. Oliyayi AR, Abolhalaj M, Zanganeh M, Zakeri MR, Rasidian A, Kazemian M, et al. [National Health Accounts Islamic Republic of Iran]. 1th ed. Tehran: fate makers; 2008.

26. Kazemian M. Financial indicators in health care sector. Social Security Quarterly 2006; 26: 45-8.

27. The World Bank Group, Human Development Sector, Middle East and North Africa. Islamic Republic of Iran Health Sector Review [Internet]. 2007. Available from: http://medolympiad.behdasht.gov. ir/uploads/280_954_First_Modiriat3.pdf.

28. Baghbanian A. Health scope in iran: the way forward. Health Scope 2012; 1: 50-1.

\section{Key Messages}

Implications for policy makers

- Healthcare financing in Iran is considered as a mixed model in which health resources are mobilized by general revenue of government, social insurances and private sector.

- Low share of government in healthcare financing, high share of Out-of-Pocket (OOP) payment, and the weak role of insurances in risk polling indicate that there are failures in financing and the objective of "equitable participation in financing" has not yet been met.

- As compared with World Bank report, indicators of this study were financially close to low-income countries level.

- To accomplish the aims of equal access to health services and fair financial protection, PHA and NHA studies can provide evidence for policy-makers, particularly in developing countries to monitor and evaluate the current situation in order to adopt appropriate interventions.
Implications for public

Provincial Health Accounts (PHA) as a subset of National Health Accounts (NHA) present financial information for health sectors at a province level. It leads to a logical decision making for policy-makers in order to achieve health system goals, especially fair financial contribution. The research indicates that the role of insurance and government in financing the Iranian health system is weak and financial pressures lead to high household out-of-pocket expenditures, particularly for poor people. Therefore, to achieve fair financial contribution goal, health system reform is necessary in Iran; especially healthcare financing and health services provision. 